DOI 10.5216/ia.v45i3.64627

\title{
PRÁTICAS PEDAGÓGICAS EM CIÊNCIAS EM UMA ESCOLA DO CAMPO
}

\author{
VALDENIR DE SOUZA COUTINHO \\ ILMA FERREIRA MACHADO \\ Universidade do Estado de Mato Grosso (UNEMAT), Cáceres, Mato Grosso, Brasil.
}

\begin{abstract}
Resumo: Este texto baseia-se em uma pesquisa de mestrado e busca analisar como acontecem as práticas pedagógicas em Ciências em uma escola do campo e de que forma elas contemplam as orientações curriculares da educação do campo. Utilizou-se metodologia de pesquisa qualitativa, com questionários semiestruturados, observação e análise documental; os sujeitos são educadoras de uma escola estadual de Mirassol D'Oeste-MT. Os resultados apontam: rotatividade de educadores; currículo com poucos elementos da educação do campo; falta de familiaridade com a teoria da educação do campo, além de dificuldade em realizar uma prática pedagógica que valorize os saberes e a realidade dos alunos do campo, o trabalho coletivo e a agroecologia. Cabe assegurar melhores condições de trabalho aos educadores, além de investimentos na formação continuada, de modo a aprofundar conhecimentos sobre a educação do campo e ressignificar as práticas pedagógicas.
\end{abstract}

Palavras-chave: Educação do campo. Escolas do campo. Práticas pedagógicas. Ciências.

\section{INTRODUÇÃO}

A educação do campo, conforme defendida pelos movimentos sociais do campo, deve ajudar a (re)construir a vida dos trabalhadores desse espaço, manter ou resgatar suas culturas e identidades, mediante a organização de projetos sociais e produtivos, além de escolas que tenham projeto político-pedagógico, currículos e práticas pedagógicas articuladas à realidade do campo, principalmente. Como ressalta Kolling et al. (1999), trata-se de um projeto educativo que busca articular as práticas de educação básica do campo a um projeto de sociedade e valorizar a cultura do campo, entre outros aspectos. Nessa mesma linha, Caldart $(2015$, p. 4) argumenta que não é possível descolar a discussão sobre educação do campo "das questões do trabalho, da cultura, do embate de projetos de campo, e hoje, de modelos ou lógicas de agricultura, que têm implicações sobre projeto de país, de sociedade e sobre concepções de política pública, de educação, de formação humana".

Nesse projeto educativo, destacamos o compromisso de educadores e educadoras das escolas do campo com a prática pedagógica, que é caracterizada por intencionalidades, portanto, "como uma ação consciente e participativa, que emerge da multidimensionalidade que cerca o ato educativo" (FRANCO, 2016, p. 536), que tem 
como propósito concretizar processos pedagógicos. Para Souza (2016), a prática pedagógica envolve diversos fatores, vinculando-se

\begin{abstract}
aos conteúdos, à relação do educador com o educando, às técnicas de ensino, a avaliação, aos materiais didático-pedagógicos e às tecnologias educacionais [...] tem sujeitos, mediações e conteúdos que podem estar no mundo escolar ou fora dele. Ela pode estar voltada para reforçar relações de dominação ou fortalecer processos de resistência. Com uma ou outra intencionalidade ela continua sendo uma dimensão da prática social (p. 38).
\end{abstract}

A prática pedagógica guarda relação com o contexto social mais amplo, inserindo-se no âmbito do trabalho social. Por isso, é considerada como "uma dimensão da prática social, que pressupõe a relação teoria-prática, e é essencialmente nosso dever, como educadores, a busca de condições necessárias à sua realização" (VEIGA, 1994, p. 16).

O desenvolvimento da prática pedagógica tem sido desafiador para muitos educadores/as e suscitado diversos estudos no Brasil, entre eles, destacamos, aqui, três pesquisas. Cardoso (2009) interrogou sobre as práticas pedagógicas dos professores de ciências de uma escola sergipana, no intuito de compreender de que maneira são desenvolvidas. A autora concluiu que, em suas práticas pedagógicas, os professores demonstram conhecer o contexto vivenciado pelas comunidades locais, porém esse conhecimento não supera o senso comum, construído historicamente sobre a zona rural. Luz (2018) realizou pesquisa no interior do estado do Paraná, no sentido de saber como se desenvolve a prática pedagógica de uma escola multisseriada. A autora registrou que, mesmo com os desafios enfrentados, inclusive com ameaças de fechamento da escola, a professora articulou-se com a comunidade para evitar o fechamento, redimensionou o planejamento na perspectiva da formação humana dos sujeitos e dos princípios da Educação do Campo, conseguindo realizar " uma prática pedagógica que valoriza a identidade dos povos do campo, que consegue articular os aspectos da realidade dos sujeitos, cultural, social e econômico, com o conhecimento de mundo" (LUZ, 2018, p. 543). A pesquisa de Poloniato (2017) tratou sobre a legislação da educação do campo e práticas pedagógicas em um assentamento da reforma agrária, em Mato Grosso, concluindo que, embora existam legislações específicas para a educação do campo, ainda há adaptações quanto ao currículo e calendário escolar, sustentando os paradigmas da educação capitalista. Mas, ao mesmo tempo, mostra que há uma prática pedagógica em movimento, posto que "há por parte dos trabalhadores/professores, a vontade, o querer romper com a lógica tradicional, atravessada pela burocracia, que emperra o processo, o fazer diferente" (POLONIATO, 2017, p. 78).

Portanto, esses estudos são significativos do ponto de vista da compreensão das práticas pedagógicas em escolas do campo, além de contribuírem com a pesquisa que realizamos sobre práticas pedagógicas em Ciências, na realidade específica de uma escola, no estado de Mato Grosso. 
COUTINHO, V. DE S.; MACHADO, I. F

\section{Procedimentos METOdológicos}

O presente texto trata da prática pedagógica em escola do campo e tem como objetivo analisar como se desenvolvem as práticas pedagógicas em Ciências em uma escola do campo, se/de que forma contemplam as orientações curriculares para a educação do campo e quais os desafios encontrados nesse processo.

A investigação desenvolveu-se a partir de abordagem qualitativa, tendo como instrumentos: análise documental, questionários semiestruturados e observação. $\mathrm{O}$ lócus da pesquisa foi uma escola estadual localizada no Distrito de Sonho Azul, Município de Mirassol D'Oeste/MT. A escola, aqui designada apenas pelas iniciais do nome, como J.C., atende famílias do assentamento Silvio Rodrigues, de sítios e pequenas propriedades (chácaras), além do perímetro urbano do distrito. O quadro de profissionais da Escola Estadual "J.C." é composto, em sua grande maioria, por contratados, o que explica a grande instabilidade do quadro docente e técnico; os educadores, majoritariamente, residem na cidade de Mirassol D'Oeste/MT. Essa unidade escolar, com 342 alunos, funciona, em regime de externato, nos turnos matutino, vespertino e noturno, ofertando Ensino Fundamental, Ensino Médio Regular e Educação de Jovens e Adultos.

Participaram dessa pesquisa duas educadoras que trabalham o componente curricular de Ciências nos anos finais do Ensino Fundamental. Em observância às regras estabelecidas pelo Conselho de Ética em Pesquisa, manteremos sigilo quanto à identidade dos sujeitos da pesquisa, que serão designados por nomes fictícios: professora Rosa e professora Safira. Ambas são graduadas em Ciências Biológicas e são interinas, ou seja, têm contrato funcional temporário; a primeira atua há dois anos como professora, e a segunda, há um ano.

As análises aqui realizadas se deram a partir de dados levantados no estudo do Projeto Político-Pedagógico (PPP) da escola, na leitura dos planos de ensinos de Ciências, nas respostas ao questionário e na observação da prática pedagógica dos professores participantes da pesquisa, em articulação com os teóricos que embasam este estudo.

\section{PROJETO POLÍTICO-PEDAGÓGICO DA ESCOLA ESTADUAL J.C.}

O processo histórico de criação da Escola Estadual J.C. tem ligação com o fenômeno migratório ocorrido na década de 60, que deu origem ao distrito de Sonho Azul, que está situado a $11 \mathrm{~km}$ do Município de Mirassol D'Oeste/MT e é composto por trabalhadores rurais e urbanos, diaristas com baixa renda per capita e por alguns desempregados. Embora esteja instalada em espaço considerado urbano, a escola insere-se na modalidade de escola do campo pelo fato de atender, em sua maioria, alunos residentes na zona rural - grande parte do acampamento Sílvio Rodrigues. De acordo com o Decreto 7.352/2010, artigo 10, considera-se escola do campo: "aquela situada em área rural [...] ou aquela situada em área urbana, desde que atenda predominantemente a populações do campo, e também, as turmas anexas vinculadas a escolas com sede em área urbana" (BRASIL, 2010, p. 1).

Contudo, cabe evidenciar que, do ponto de vista conceitual, "escolas DO campo são constituídas por sua identidade, não por sua localização geográfica [...] o elemento 
definidor são os sujeitos que compõem a realidade escolar, que são centrais para a construção da identidade escolar" (MARTINS, 2020, p. 28), assim como o projeto educativo elaborado e assumido coletivamente, segundo os princípios da educação do campo.

Consta que o PPP, como instrumento teórico-metodológico que baliza as ações político-administrativa e pedagógicas da escola como um todo (VEIGA, 2002; MACHADO, 2008), foi construído com a participação dos professores, coordenadores, gestão e comunidade escolar, mediante a realização de reuniões/debates com os segmentos escolares e posterior aprovação no Conselho Deliberativo Escolar (CDCE); esse processo foi acompanhado pelo Centro de Formação e Aperfeiçoamento dos Profissionais da Educação Básica (Cefapro) - regional de Cáceres/MT. Na elaboração do PPP, foram observadas as instruções normativas da Secretaria de Estado de Educação de Mato Grosso (Seduc/MT), específicas para esse fim.

Apesar de a elaboração do PPP ser coletiva, a demora na contratação de professores, a cada ano letivo, e a instabilidade do quadro docente prejudicam a participação mais efetiva dos professores nesse processo. Essas questões têm preocupado a gestão da escola, conforme registrado no documento consultado:

\begin{abstract}
Esperamos que a SEDUC viabilize os orientativos e portarias com antecedência para a atribuição de aula aconteça antes da semana pedagógica e que todos os profissionais contratados participem e inteirem dos assuntos tratados na Unidade Escolar, sem fragmentar a sua participação na construção do PPP, e reformulação do Regime Escolar, entre outras ações pedagógicas (PPP, J.C., 20017, p. 4).
\end{abstract}

O PPP é acessível aos profissionais da escola e aos pais, ficando sob a responsabilidade da coordenadora disponibilizá-lo a quem desejar conhecê-lo e estudálo. Em seu marco conceitual, esse documento traz referenciais teóricos que tratam das concepções de educação do campo, frisando que "pensar a educação do campo num processo orgânico com o desenvolvimento do campo implica pensar e construir as condições para que se estabeleça de fato a relação da escola com a vida" (MACHADO, 2008, p. 5). Para a escola J.C., a educação do campo tem caráter democrático, e é necessário estabelecer um currículo que atenda à realidade do aluno.

\begin{abstract}
A educação tem como eixo norteador a experiência e aprendizagem, fazendo com que a função da escola seja a de propiciar uma reconstrução permanente das mesmas, objetivando desenvolver a função democratizadora de igualar as oportunidades. A escola precisa contextualizar o currículo, para ministrar um conhecimento que faça sentido à vivência do aluno. Estabelecer uma relação entre o conhecimento e as ações do dia-a-dia [...] (PPP, J.C., 2017, p. 2).
\end{abstract}

Nesse contexto, a escola assume o compromisso com uma educação voltada para o sujeito do campo, que reconheça os saberes e práticas do campo como componentes da prática pedagógica. Segundo o regimento da escola (2017, p. 3), sua 
filosofia é "assegurar aos alunos o direito à aprendizagem, respeitando o processo de desenvolvimento humano e a diversidade existente, proporcionando-lhes condições de construir sua identidade e autonomia de forma integrada e interdisciplinar".

Conforme disposto no regimento escolar e no PPP, a escola se compromete em assegurar ao aluno o direito a uma educação de qualidade - condição indispensável para o exercício da cidadania - e dar condições para o desenvolvimento de suas potencialidades no âmbito escolar e na comunidade onde ele está inserido: "a escola deve contribuir para a formação do ser humano, cultivando atitudes de solidariedade, de respeito à vida, na preservação do meio ambiente, que repudie qualquer tipo de injustiça e de conivência com a corrupção" (PPP, J.C., 2017, p. 2).

De acordo com Veiga (2002, p. 13), a dimensão pedagógica do PPP diz respeito às "ações educativas e as características necessárias às escolas de cumprirem seus propósitos e sua intencionalidade". Ao analisar o PPP da escola, constata-se que as proposições apresentadas não se voltam para a especificidade da educação do campo trabalho e cultura dos sujeitos do campo, relação com a terra e o meio ambiente etc.

Mesmo embasada em concepções teóricas da educação do campo, a escola apresenta um currículo fragmentado, construído com base no orientativo da Seduc/MT, com fortes características de currículo urbano, sem articular com as orientações curriculares das diversidades educacionais de Mato Grosso e sem apresentar proposições que dialoguem mais efetivamente com realidade local. As orientações curriculares das diversidades apontam para a construção das práticas pedagógicas da educação do campo, partindo do princípio de que a escola do campo tem profunda relação com a agricultura e a vida camponesa (MATO GROSSO, 2010). Entre as práticas pedagógicas indicadas no documento, destacamos:

a) Vinculação, articulação interativa com a vida e a realidade dos povos dos campos, suas lutas e experiências, seus saberes e suas organizações e seus movimentos, e limites e potencialidades.

b) Compromisso de realizar o processo ensino-aprendizagem respeitando, valorizando e incorporando saberes, experiências e conhecimentos dos povos do campo;

c) Articulação e promoção dos diversos espaços e tempos pedagógicos:

d) Compromisso com a transformação do campo, a partir dos projetos emancipatórios dos povos do campo (MATO GROSSO, 2010, p. 131).

No PPP da escola, nota-se preocupação em se alcançar melhor rendimento escolar e desempenho nas avaliações internas e avaliações externas - Avaliação Diagnóstica do Ensino Público Estadual (ADEPE), Sistema de Avaliação da Educação Básica (SAEB) etc. No entanto, o cumprimento das exigências avaliativas conflita com uma maior autonomia na organização dos tempos e espaços pedagógicos. A escola aponta dificuldades em relação à prática pedagógica e, também, desejo em superá-las.

Desejamos que a proposta pedagógica seja elaborada e incorporada nas práticas diárias [...] e que a matriz curricular, o calendário e currículo proporcionem equilíbrio entre as atividades, 
fazendo com que os alunos se envolvam por si próprio, e em algo coletivo (PPP, J.C., 2017, p. 3).

É pertinente destacar que, mesmo que a organização curricular da escola não tenha um enfoque mais explícito na educação do campo, é possível identificar no PPP da Escola J.C. indicativos de atividades a serem desenvolvidas na perspectiva de uma prática pedagógica que articule conteúdos escolares, saberes dos educandos, realidade da comunidade e desenvolvimento social local, como por exemplo:

\begin{abstract}
[...] despertar nos alunos, nos educadores (professores, funcionários e familiares), o interesse, para juntos criarem um projeto de sustentabilidade, para que possamos implantar ações que façam da escola um ambiente organizado, inclusive aproveitar melhor a área, criando canteiros, trabalhando a revitalização verde do espaço e planejando uma solução para a utilização de todo espaço físico que a escola dispõe. [...] parceria com associações de catadores, para que venham à escola explicar aos alunos seu trabalho e o destino dado aos materiais e trabalhar a reciclagem, o reaproveitamento do lixo para despertar no aluno o interesse em aprender sobre a importância de cuidar do meio ambiente (PPP, J.C., 2017, p. 6).
\end{abstract}

Essas proposições pedagógicas apontadas no PPP trazem possibilidades de se vincular o processo ensino-aprendizagem com os saberes dos sujeitos do campo e, assim, realizar práticas pedagógicas críticas e contextualizadas, que propiciem estabelecer uma relação dinâmica entre teoria-prática e ampliar o conhecimento dos alunos, tanto sobre a sua própria realidade quanto sobre a realidade mais ampla, a exemplo do que Poloniato (2017) e Luz (2018) apontaram em seus estudos.

As práticas pedagógicas articulam-se em torno do eixo curricular. Por isso, é importante pensar em um currículo para a educação do campo que valorize os saberes do educando e suas vivências socioculturais. Como afirma Klein (2013, p. 188), "os conteúdos escolares devem ser redimensionados a partir do contexto e da cultura dos sujeitos do campo". E, para Caldart (2009, p. 46), os profissionais das escolas do campo devem ser capazes "de coordenar a construção de um currículo que contemple diferentes dimensões formativas e que articule o trabalho pedagógico na dimensão do conhecimento com práticas de trabalho, cultura, luta social". O documento das orientações curriculares das diversidades/MT pode contribuir com essa discussão ao propor que o currículo das escolas do campo considere pelo menos quatro temáticas pedagógicas: a construção da cidadania; terra e trabalho; os povos do campo: identidades, lutas e organizações; e sociedades sustentáveis (MATO GROSSO, 2010).

\title{
OS PLANOS DE ENSINO DE CIÊNCIAS E AS POSSÍVEIS ARTICULAÇÕES COM O PPP
}

No PPP, indica-se a necessidade de que os professores estabeleçam uma relação entre plano de ensino, currículo e projeto político-pedagógico. Para a escola, o plano de ensino precisa estar em consonância com o PPP e articulado com a prática pedagógica dos professores. Nesse sentido, faz-se necessário um planejamento de ensino que 
"atenda a todos os alunos, independente da capacidade que eles venham a apresentar, respeitando as necessidades de cada um, por meio de atitudes simples no dia-a-dia, execução de projetos interdisciplinares voltados para o ensino aprendizagem" (PPP, J.C., 2017, p. 4).

No entanto, a contratação e a mobilidade de professores durante o ano letivo têm causado transtornos para a organização do trabalho pedagógico - construção do PPP, dos planos de ensinos e dinâmica das aulas -, fazendo com que, nem sempre, as orientações contidas no PPP sejam observadas na prática. A Professora Rosa, recémcontratada, alega não ter conhecimento do PPP: "Não conheço, devido a ter sido contratada após a construção do mesmo" (Rosa-JC, 28/6/2018). Vale ressaltar que nem todos os planos de ensino analisados foram elaborados pelos professores de Ciências que participaram da pesquisa, uma vez que houve mudanças de professores devido à não renovação de contratos funcionais ou afastamento por licença.

A rotatividade de professores na escola é um aspecto que compromete a prática pedagógica e a relação professor-aluno, interferindo diretamente no ensino/aprendizagem, pois, como ressalta Arroyo (2012), isso acaba impossibilitando a constituição de um grupo de profissionais identificados e habilitados para a educação básica dos povos do campo; o problema torna-se ainda maior quando o professor contratado nem sempre conhece a realidade do sujeito do campo. Essa é uma situação vivenciada também em outras regiões brasileiras e abordada em outras pesquisas, a exemplo de Cardoso (2009), que diz que é necessário refletir sobre a rotatividade desses profissionais nas escolas e se pergunta como poderão ocorrer os "processos de interação entre professores com a realidade do aluno em tão pouco espaço de tempo" (CARDOSO, 2009, p. 81).

Ao analisar os planos de ensino de Ciências, foi possível constatar que os conteúdos se organizam segundo o Orientativo da Seduc/MT, apresentando pouca relação entre conteúdos e metodologias adotadas pelos professores, com a realidade do campo, e as Orientações Curriculares para a educação do campo, que oferecem indicativos de como organizar o currículo e as práticas pedagógicas nas escolas do campo de Mato Grosso. O plano de ensino é flexível, mas o Orientativo da Seduc/MT tem comprometido esse princípio, uma vez que, ao registrar as atividades pedagógicas no sistema SigEduca, os professores têm que seguir a proposta da Seduc/MT, caso contrário, são cobrados pelo não cumprimento.

As propostas metodológicas - e os materiais didáticos - apresentadas nos planos de ensino de Ciências foram: aulas expositivas e dialogadas; interpretação dos fatos; leituras de textos informativos; atividades do livro didático; exercícios de fixação; vídeos; documentários; entre outros. Portanto, algo semelhante a outras escolas, principalmente, às urbanas. Tanto os planos de ensino da professora Safira-JC quanto os da professora Rosa-JC apresentam propostas de avaliação qualitativa, cujos instrumentos avaliativos constam de realização de tarefas em sala e extra sala, participação nas atividades, testes e provas, guardando relação com o que está disposto no PPP e no Regimento Escolar.

Os planos de ensino de Ciências do $6^{\circ}$ ao $9^{\circ}$ ano, apesar de basearem-se no PPP da escola JC, não incorporam dimensões que ele apresenta, de uma prática pedagógica voltada à realidade da escola do campo, tais como: desenvolvimento de um projeto de sustentabilidade ambiental revitalização do espaço verde, reciclagem e possibilidade de parceria com associação de catadores.

Inter-Ação, Goiânia, v.45, n.3, p. 1002-1016, set./dez. 2020. Disponível em: <http://dx.doi.org/10.5216/ia.v45i3.64627>. 


\section{AS PRÁTICAS PEDAGÓGICAS EM CIÊNCIAS NA ESCOLA ESTADUAL J.C.}

As práticas pedagógicas no ensino de Ciências, na escola J.C., no ano de 2018, tiveram um período de instabilidade, devido à rotatividade de professores, foram diversas substituições até se estabilizarem em março desse mesmo ano. As aulas de Ciências, nos anos finais do Ensino Fundamental, no período de observação, foram ministradas pelas professoras "Rosa" e "Safira".

A professora Rosa trabalhou com o $6^{\circ}$ Ano A (matutino), $6^{\circ}$ Ano B (vespertino) e $8^{\circ}$ Ano $A$ (matutino). Nas turmas de $6^{\circ}$ ano, ela desenvolveu o trabalho de acordo com o plano de ensino, com aulas expositivas e dialogadas, e interpretação de fatos. Segundo a professora Rosa, a prática pedagógica em Ciências para a educação do campo deve priorizar "atividades que estimulam a criatividade dos alunos, atividades em grupos, fora da sala de aula, uso de tecnologia, debates, aula prática e recortes" (Rosa, 28/6/2018).

Com as turmas do $6^{\circ}$ ano, a professora Rosa realizou, também, aula prática sobre "Fotossíntese e Respiração Celular", utilizando o espaço externo da escola para demonstrar o processo de fotossíntese e a importância das plantas para o meio ambiente. Ainda como parte dessa aula, de forma interdisciplinar, ela desenvolveu, junto com a professora e a turma da sala de recurso multifuncional - destinada ao Atendimento Educacional Especializado - AEE -, plantio de ipê e outras espécies no pátio da escola. Essa prática possibilitou articular teoria e prática, tornando as aulas vivas e prazerosas, propiciando maior aprendizado para os alunos, que tiveram expressiva participação nas aulas, com indagações, opiniões e questionamentos, além dos bons resultados nas avaliações.

Em outra prática, a professora Rosa organizou uma visita a uma caverna e trilha na serra (Pé da Serra), no bairro Jardim São Paulo, a cerca de $2 \mathrm{~km}$, próximo à cidade de Mirassol D'Oeste/MT, onde foi possível analisar o processo erosivo e a formação das rochas, como também trabalhar a interação pessoal dos alunos e vivenciar os conteúdos abordados em sala de aula. Na oportunidade, puderam estudar o processo de formação do solo, conhecer alguns tipos de rochas, bem como dialogar sobre a importância de preservar os recursos naturais. A possibilidade de ministrar aulas práticas depende do componente curricular de cada ano/turma, conteúdos abordados e condições estruturais para tal - suporte financeiro e material, como também do interesse, da disposição e criatividade do professor. Nesse sentido, a professora Rosa desenvolveu aulas dinâmicas com $06^{\circ}$ ano, se desapegando um pouco dos livros didáticos, movimentando-se, também, na perspectiva de construção e práticas pedagógicas mais afinadas com a lógica da escola do campo, que busca "valorizar a cultura, os saberes e os modos de vida no campo" (LUZ, 2018, p.356), além de contribuir para que os sujeitos do campo possam compreender e transformar o lugar onde vivem.

Observando a prática pedagógica da professora Rosa, no $8^{\circ}$ ano, nota-se o uso fiel do livro didático, com poucos recursos e poucas práticas diferenciadas. Os conteúdos foram abordados por meio de leituras e atividades no livro didático, pesquisas bibliográficas e trabalhos escritos em grupo.

Em diálogo com a professora Rosa, sobre o interesse e a participação dos alunos nas discussões em sala de aula, ela alegou que há maior participação dos alunos nas 
discussões relacionadas aos seres vivos e cadeia alimentar, acreditando que é por se tratarem de assuntos mais próximos da realidade dos alunos do campo, o que propicia uma interação mais efetiva com os alunos da zona urbana.

Desenvolver práticas pedagógicas, na perspectiva de atender a realidade do povo do campo, ainda é um desafio para o professor de Ciências, como mencionado pela professora Rosa, em resposta ao questionamento: "Você encontra dificuldades em sua prática pedagógica em Ciências na escola do campo?" "Sim, devido à falta de um laboratório de Ciências e de materiais que auxiliam na execução de aulas práticas". Reiterando o que diz a professora, faltam também livros didáticos para todos os alunos, laboratório de informática equipado com internet e com potencial para pesquisa, além de formação e capacitação específica para educadores e educadores do campo.

Seria importante que o PPP da escola "J.C." tivesse um currículo voltado para a educação do campo e que promovesse formação continuada sobre as concepções e práticas da educação do campo, atentando-se ao atendimento às diversidades contempladas na Resolução 01/2002, além das Orientações Curriculares das Diversidades Educacionais do Estado de Mato Grosso (MATO GROSSO, 2010), de modo especial, no capítulo que trata da educação do campo. Isso contribuiria para melhorar e ampliar o alcance dos objetivos da disciplina no contexto do campo, bem como para melhorar a articulação entre a prática pedagógica e a realidade do sujeito do campo, incorporando os saberes, valores e outros elementos que caracterizam a identidade do campo.

Na prática pedagógica desenvolvida nos $7^{\circ}, 8^{\circ}$ e $9^{\circ}$ anos pela professora Safira, observa-se a predominância de aulas expositivas, com pouco questionamento, com uso quase que exclusivo do livro didático, o que caracteriza uma prática pedagógica repetitiva, aquela que, segundo Veiga (1994), permite uma dissociação entre a teoria e a prática, com aulas centradas na simples transmissão de conteúdos, sem problematizálos e sem instigar os educandos com perguntas que ajudem a despertar a curiosidade deles. Essa situação corrobora a análise de que, em muitas escolas do campo, persistem adaptações curriculares e metodológicas com marcas dos "velhos paradigmas da classe dominante, enraizadas nas determinações capitalistas" (POLONIATO, 2017, p. 79).

Os princípios da educação do campo estão pouco presentes na prática pedagógica dessa professora, que alega não ter experiência de trabalho com essa modalidade de ensino: "Passei a entender a realidade desses alunos do campo a partir dessa pesquisa, até então, não tinha entendido que eu tenho que trabalhar a realidade, como que é do dia a dia deles" (Safira, 2018).

As aulas expositivas são valiosas como técnica de ensino, porém, é necessário que o professor utilize outras técnicas e instrumentos didáticos, além de não ficar preso ao livro didático, indo além dele, buscando questões e leituras complementares, colocando situações-problema que despertem o raciocínio e a criticidade do educando e, por fim, promover a participação ativa de todos eles, de modo que possam sentir-se valorizados como sujeitos e comprometidos com o processo educativo realizado na escola. Luz (2018, p.367), na pesquisa que realizou, registrou que a prática pedagógica da professora "valoriza a identidade dos sujeitos do campo e tem se mostrado na perspectiva da transformação, que pensa o sujeito na sua totalidade. Este olhar diferenciado para o campo, estabeleceu um vínculo entre a educadora, educandos e a comunidade [...]". 
Cabe ao professor explorar o material à sua disposição, seja ele didático ou paradidático, e, até mesmo, o ambiente físico. Quando perguntada se a escola oferece espaço para o desenvolvimento de projetos e atividades pedagógicas relacionadas à horta, jardinagem ou outro tipo de experiência acadêmico-científico, a professora respondeu: "a escola tem um amplo espaço externo. Existe a horta, o jardim. No entanto, ainda não fiz aula a campo. Procuro fazer com que eles pesquisem em livros e revistas e recortes para cartazes" (Safira, 2018). Durante a observação, corroborando a resposta do questionário, foi constatada dificuldade em utilizar o espaço externo escolar como suporte para a prática docente.

Durante as observações da prática pedagógica desenvolvida pela professora Safira, nos $7^{\circ}, 8^{\circ}$ e $9^{\circ}$ anos, constatamos que ela utilizou metodologia de aulas expositivas, tendo como material didático o livro e o quadro para transcrição/anotação. O uso de poucos recursos didáticos comprometeu a qualidade da aula e até mesmo a apropriação do conhecimento por parte dos alunos, o que pode se notar pela pouca participação deles e pelo resultado das avaliações escritas feitas em sala de aula - por exemplo, houve dificuldades nas resoluções de questões que envolviam cálculos de questões de química, física -, portanto. Quando o docente domina o conteúdo e consegue ministrar aulas dinâmicas, diferenciadas, acompanhadas de atividades diversas, há melhor participação dos alunos e melhor relação aluno/professor.

O professor, muitas vezes, precisa desconstruir regras, ser curioso para adentrar a realidade da escola e dos educandos, além de desenvolver práticas pedagógicas condizentes com sua realidade. Já dizia Freire (2004, p. 87): "sem a curiosidade que me move, que me inquieta, que me insere na busca, não aprendo nem ensino".

As aulas no $9^{\circ}$ ano foram, em sua maioria, expositivas, pouco problematizadas, sustentadas no livro didático, destacando a dimensão técnica do conteúdo. Notadamente, havia certa dificuldade por parte da docente em lidar com o conteúdo do $9^{\circ}$ ano. Os livros didáticos são de suma importância, mas existem outras fontes, meios, materiais paradidáticos, mencionados no plano de curso que o professor poderá utilizar, sem que corra o risco de ficar refém dessa única fonte (DELIZOICOV, 2009, p. 37).

A educação escolar pode ser subsidia por materiais paradidáticos e tecnológicos, porém, "é imperativo seu uso crítico e consciente pelo docente de Ciências de todos os níveis de escolaridade, particularmente no segmento da quinta a oitava série" (DELIZOICOV 2009, p. 37). Além disso, as escolas do campo dispõem do ambiente natural como grande aliado no desenvolvimento de suas práticas pedagógicas, favorecendo a realização de estudos e experimentos científicos. Há que se ressaltar que os professores se ressentem da falta de laboratório de Ciências.

A metodologia utilizada pelos professores, especificamente pela professora Safira, centrada em poucos recursos didáticos, aliada à falta de conhecimento sobre a realidade das famílias camponesas, evidenciou a pouca articulação da prática pedagógica com os princípios da educação do campo.

Concordamos com Oliveira e Campos (2012), que argumentam sobre a necessidade de se investir na formação inicial e continuada de educadores e gestores das escolas do campo, na elaboração de materiais didáticos contextualizados e na implementação de metodologias participativas e investigativas, na perspectiva de 
desenvolvimento de práticas pedagógicas coerentes com a concepção de educação do campo e com as necessidades da escola do campo.

\section{CONSIDERAÇÕES FINAIS}

Procuramos, neste texto, analisar de que forma se desenvolvem as práticas pedagógicas em Ciências, no Ensino Fundamental II, em uma escola do campo, e quais os principais desafios encontrados nesse processo.

Os resultados da pesquisa apontam que os professores de Ciências apresentam dificuldades no desenvolvimento de uma prática pedagógica articulada aos princípios da educação do campo. Os principais desafios encontrados nas práticas pedagógicas em Ciências, na escola J.C., são: adquirir material pedagógico coerente com a realidade do campo e em quantidade suficiente, superar a rotatividade e instabilidade dos profissionais da educação, organização curricular - que não contempla as especificidades da escola do campo - e a implementação de formação continuada voltada para os profissionais da educação, de modo especial, no componente curricular de Ciências.

É importante ressaltar que, mesmo diante das dificuldades enfrentadas, os professores têm procurado, no desenvolvimento de suas práticas pedagógicas, articular os conceitos centrais dos temas de estudo de Ciências com situações da educação do campo, além de considerarem o cotidiano dos alunos, porém, sem uma sistematicidade maior.

A consolidação de uma educação pensada com e para o sujeito do campo é um dos principais desafios das escolas do campo, posto que a lógica que vinha predominando até bem pouco tempo era a de uma escola de padrão universal e urbano, que desconsiderava as diversidades sociais e culturais do campo. A escola e os profissionais da educação do campo necessitam de uma preparação sob essa nova ótica, cabendo ao Estado prover as condições de trabalho apropriadas (qualificação, plano de carreira, equipamentos e materiais didáticos, currículo apropriado etc.).

Para Arroyo (2007, p. 169), "um dos determinantes da precariedade da Educação do Campo é a ausência de um corpo de profissionais que vivam junto às comunidades rurais, que sejam oriundos dessas comunidades". Na impossibilidade de todos esses profissionais residirem nessas comunidades rurais, há que se assegurar que tenham formação apropriada, afinidade e sensibilidade com a cultura do campo, além de compromisso com a escola do campo. Segundo Arroyo (2012), uma das contribuições da concepção de formação dos profissionais da educação do campo para a formação de todo profissional da educação básica é reconhecer os saberes do trabalho, da terra, das experiências e das ações coletivas sociais e legitimar esses saberes como componentes teóricos dos currículos.

Ser educador em escola do campo é uma tarefa árdua, como diz Kolling (2002), exige reconhecer a existência do campo e a realidade histórica do sujeito; entender a educação como fator de desenvolvimento e formação humana; compreender a relação do trabalho na formação de grupos e na produção da vida; participar das lutas sociais do campo, das lutas por políticas públicas; compreender a dinâmica dos movimentos sociais; e entender que algumas de suas pedagogias podem ser incorporadas e refletidas nas práticas de outras escolas e em nossas teorias de educação. Conforme 
Molina (2002, p. 38), "educador do campo é aquele que contribui com o processo de organização do povo do campo".

Cabe à escola do campo proporcionar à criança e ao jovem uma formação ampla, que articule conhecimento científico, tecnologia, cultura e trabalho, de modo a contribuir com a transformação não apenas dos estudantes, mas da comunidade na qual eles vivem. As práticas pedagógicas constituem elemento importante nesse contexto, haja vista que as finalidades educativas da escola se manifestam através delas; há que se aprimorá-las na perspectiva da educação do campo, servindo-se dos referenciais teóricos e legais já constituídos nessa modalidade educativa, além da apropriação de experiências pedagógicas em andamento em diversas partes do Brasil.

Esse é um dos grandes desafios que está colocado para as escolas do campo no atual cenário brasileiro. Pois, vivenciamos, desde 2016, um processo sistemático e continuado de desmonte das políticas públicas, de modo especial em relação à agricultura familiar e camponesa e à educação do campo. O projeto político que está em curso em nosso país privilegia o capital, o agronegócio, o latifúndio, desprezando o campo da agricultura familiar, os indígenas e quilombolas, além de outros trabalhadores rurais, como sujeitos de direitos. Com isso, ampliam-se as desigualdades sociais e desumanização. Portanto, a luta pela construção da escola do campo é, também, uma luta por políticas públicas e pela superação do projeto de sociedade capitalista.

Artigo recebido em: 23/07/2020

Aprovado para publicação em: 03/11/2020

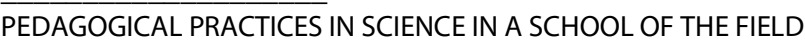

ABSTRACT: This text is based on a master's research, and seeks to analyze how pedagogical practices in science happen in a field school, and how they contemplate the curricular orientations of field education. A qualitative research methodology was used, with semi-structured questionnaires, observation and documentary analysis; the subjects were educators of a state school in Mirassol D'Oeste-MT. The results indicate: turnover of educators; curriculum with few elements of field education; lack of familiarity with the theory of field education, and difficulty in performing a pedagogical practice that values the knowledge and reality of students in the field, collective work and agroecology. It is important to ensure better working conditions for educators, and invest in continuing education, in order to deepen knowledge about the education of the field, and resignify pedagogical practices.

KEYWORDS: Countryside education. Country schools. Pedagogical practices. Sciences.

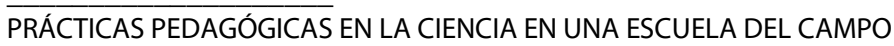

RESUMEN: Este texto se basa en una investigación de maestría, y busca analizar cómo ocurren las prácticas pedagógicas en ciencia en una escuela de campo, y cómo contemplan las orientaciones 
COUTINHO, V. DE S.; MACHADO, I. F.

curriculares de la educación del campo. Se utilizó metodología de investigación cualitativa, con cuestionarios semiestructurados, observación y análisis de documentos; los sujetos eran educadores en una escuela pública en Mirassol D'Oeste-MT. Los resultados muestran: rotación de educadores; currículo con pocos elementos de educación rural; desconocimiento de la teoría de la educación del campo, y dificultad para realizar una práctica pedagógica que valore el conocimiento y la realidad de los estudiantes en el campo, el trabajo colectivo y la agroecología. Es necesario asegurar mejores condiciones de trabajo para los educadores e invertir en la educación continua, para profundizar el conocimiento sobre la educación del campo y resignificar las prácticas pedagógicas.

PALABRAS CLAVE: Educación del campo. Escuelas del campo. Prácticas pedagógicas. Ciencias.

\section{REFERÊNCIAS}

ARROYO, M.G. Formação de Educadores do Campo. In: CALDART, R. S. et al. Dicionário de Educação do Campo. Rio de Janeiro, São Paulo: Escola Politécnica de Saúde Joaquim Venâncio, Expressão Popular, 2012. 788p.

ARROYO, M.G. Políticas de formação de educadores (as) do campo. Caderno Cedes, Campinas, v. 27, n. 72, p. 157-176, maio/ago. 2007. Disponível em: https://www.scielo.br/pdf/ccedes/v27n72/a04v2772.pdf. Acesso em 5 jun. 2018.

BRASIL. Decreto n. 7.352 de 4 de novembro de 2010. A política de educação do campo e o Programa Nacional de Educação na Reforma Agrária - PRONERA. Disponível em: http://portal.mec.gov.br/docman/marco-2012-pdf/10199-8-decreto-7352-de4-denovembrode-2010/file. Acesso em 20 jun. 2018.

CALDART, R.S. Educação do campo: notas para uma análise de percurso. Trabalho, educação e saúde, Rio de Janeiro, v. 7, n. 1, p. 35-64, 2009.

CALDART, R.S. Sobre a especificidade da Educação do Campo e os desafios do momento atual. Disponível em file:///C:/Users/Windows/Downloads/EdoCDesafiosMomentoAtual-Roseli-Jul15.pdf. Acesso em 07 nov. 2020.

CARDOSO, L.R. Processo de recontextualização de ciências da escola do campo: a visão de professores do Sertão Sergipano. 2009. 179f. Dissertação (Mestrado em Educação) - Universidade Federal de Sergipe, São Cristovão, SE, 2009.

DELIZOICOV, D. et al. Ensino de Ciências: Fundamentos e Métodos. 3 ed. São Paulo: Cortez, 2009. 364p.

FRANCO, M.A.R.S. Prática pedagógica e docência: um olhar a partir da epistemologia do conceito. Rev. Bras. Estud. Pedagog. (on-line), Brasília, v. 97, n. 247, p. 534-551, set./dez. 2016. Disponível em https://www.scielo.br/scielo.php?pid=S217666812016000300534\&script=sci_abstract\&tlng=pt. Acesso em 03 nov. 2020. 
FREIRE, P. Pedagogia da Autonomia. Coleção leitura, 29. ed. São Paulo: Paz e Terra, 2004. 143p.

KLEIN, S. F. Educação do campo: um estudo sobre cultura e currículo na escola municipal de ensino fundamental Crubixá - Alfredo Chaves - Espírito Santo. 2013. 225f. Dissertação (Mestrado em Educação) - Universidade Federal do Espírito Santo, Vitória, 2013.

KOLLING, E. J. et al. Educação do campo: Identidades e Políticas Públicas. Brasília, DF: Articulação Nacional Por uma educação básica do campo. 2002. 136p.

KOLING. E. J. et al. Por uma educação básica do campo. Brasília: Fundação Universidade de Brasília, v. 1, 1999. 98p.

LUZ, L.A. Prática pedagógica em escola multisseriada: olhares da professora. In: SOUZA, M.A. (Org.). Escola pública, educação do campo e projeto político-pedagógico. Curitiba: UTP, 2018. p.337-370

MACHADO, I. F. Qual a organização curricular necessária a escola do campo? IV Colóquio Luso-Brasileiro sobre questões curriculares. Universidade Federal de Santa Catarina, Florianópolis, 2008. p.1-12.

MARTINS, F.J. A escola e a educação do campo. São Paulo: Pimenta Cultural, 2020. $179 p$.

MATO GROSSO. Secretaria de Estado e Educação de Mato Grosso. Orientações Curriculares das Diversidades Educacionais. Cuiabá: Defanti, 2010. 308p.

MOLINA, M.C. Desafios para os educadores e as educadoras do campo. In:KOLLING, E. J. et al. Educação do campo: Identidades e Políticas Públicas. Brasília, DF: Articulação nacional por uma educação básica do campo. 2002. 136p.

OLIVEIRA, L. M. T.; CAMPOS, M. Educação Básica do Campo. In: CALDART, R. S. et al. Dicionário de Educação do Campo. Rio de Janeiro, São Paulo: Escola Politécnica de Saúde Joaquim Venâncio, Expressão Popular, 2012. 788p.

POLONIATO, S. O assentamento de reforma agrária Wesley Manoel dos Santos: legislação e práticas pedagógicas. In:PERIPOLLI, O.J. et al. (Org.). Formação continuada: o diálogo necessário entre a universidade e os educadores do campo. Lajeado: Editora da Univates, 2017. p.65-80

PROJETO POLÍTICO-PEDAGÓGICO. Escola Estadual J.C., Distrito de Sonho Azul, Município de Mirassol D Oeste, Mato Grosso, 2017.

REGIMENTO ESCOLAR. Escola Estadual J.C., Distrito de Sonho Azul, Município de Mirassol D'Oeste, Mato Grosso, 2018.

Inter-Ação, Goiânia, v.45, n.3, p. 1002-1016, set./dez. 2020. Disponível em: <http://dx.doi.org/10.5216/ia.v45i3.64627> 
COUTINHO, V. DE S.; MACHADO, I. F.

SOUZA, M.A. Sobre o Conceito de Prática Pedagógica. In: SILVA, M.C.B. (Org.). Práticas pedagógicas e elementos articuladores. Curitiba: Universidade Tuiuti do Paraná, 2016. p.38-65

VEIGA, I. P. A. A prática pedagógica do professor de didática. 3 ed., Campinas: Papirus, 1994, 192p.

VEIGA, I. P. A. Projeto político-pedagógico da escola: uma construção coletiva. In: VEIGA, I. P. A. (Org.). Projeto político-pedagógico da escola: uma construção possível. 14 ed., Campinas: Papirus, 2002. p.11-35.

Valdenir de Souza Coutinho. Graduado em Ciências Biológicas pelo Centro Universitário de Várzea Grande (UNIVAG). Especialista em Educação Ambiental pelo Instituto Cuiabano de Educação (ICE). Mestre em Educação pela Universidade Estadual de Mato Grosso (UNEMAT). Professor de uma escola campo da rede estadual de ensino de Mato Grosso, atuando no componente curricular de Ciências Biológicas - no Ensino Fundamental Anos Finais e no Ensino Médio.

Orcid: https://orcid.org/0000-0003-1708-3773

E-mail: valdenirsouzacoutinho@hotmail.com

Ilma Ferreira Machado. Graduada em Pedagogia pela Universidade Federal de Mato Grosso (UFMT). Mestre e Doutora em Educação pela Universidade Estadual de Campinas (Unicamp). Pós-doutorado pela Universidade Federal de Santa Catarina (UFSC). Professora sênior da Universidade do Estado de Mato Grosso (UNEMAT), no Programa de Pós-graduação em Educação, vinculada à linha Educação e diversidade". Orcid: http://orcid.org/0000-0001-5253-7684

E-mail: ilma.ferreiramachado@gmail.com

Este periódico utiliza a licença Creative Commons Attribution 3.0, para periódicos de acesso aberto (Open Archives Iniciative - OAI). 